\title{
Morfologia da árvore brônquica de pulmões de quatis (Nasua nasua, Linnaeus, 1966)
}

\author{
Amilton Cesar dos Santos ${ }^{1 *}$ \\ Bruno Machado Bertassoli ${ }^{1}$ \\ Vanessa Cristina de Oliveira ${ }^{1}$ \\ Aline Fernanda de Souza ${ }^{1}$ \\ Ricardo Alexandre Rosa ${ }^{2}$ \\ Ana Flávia Carvalho \\ Celina Almeida Furlanetto Mançanares ${ }^{1}$ \\ ${ }^{1}$ Faculdade de Medicina Veterinária e Zootecnia, Departamento de Cirurgia \\ PPG em Anatomia dos Animais Domésticos e Silvestres, Universidade de São Paulo \\ Avenida Professor Dr. Orlando Marques de Paiva, CEP 05508-270, São Paulo - SP, Brasil \\ ${ }^{2}$ Departamento de Ciências Morfológicas \\ Centro Universitário da Fundação de Ensino Octávio Bastos, Campus II \\ Parque dos Jequitibás, CEP 13874-159, São João da Boa Vista - SP, Brasil \\ *Autor para correspondência \\ amiltonsantoss@bol.com.br
}

Submetido em 30/11/2010

Aceito para publicação em 11/04/2011

\section{Resumo}

O quati (Nasua nasua) é um procionídeo de hábito diurno, terrestre e arborícola. Esses animais forrageiam extensivamente no chão e utilizam as árvores para nidificarem, repousarem durante a noite e se refugiarem. Sua dieta é onívora, consomem pequenos invertebrados, frutos, néctar, pequenos vertebrados, ovos e vegetais. $\mathrm{O}$ objetivo deste trabalho foi caracterizar microscopicamente a árvore brônquica do quati. Foram utilizados quatro quatis adultos (dois machos e duas fêmeas) provenientes do Criatório Científico CECRIMPAS - UNIFEOB (IBAMA-02027.003731/04-76) fixados em formaldeído a 10\%, provenientes de outras pesquisas realizadas na instituição referida. Para esta pesquisa as amostras de tecidos foram incluídas em parafina através de técnica de rotina e processadas para microscopia de luz em coloração de H.E e analisadas em microscópio de luz. Constatou-se que microscopicamente a árvore brônquica do quati é semelhante a dos demais mamíferos descritos na literatura consultada, ou seja, possui grandes variações em sua arquitetura, como diminuição da altura do epitélio que muda de pseudo-estratificado ciliado nos maiores brônquios para cúbico nos menores bronquíolos, ausência de cílios e glândulas nos menores bronquíolos, e decréscimo no diâmetro e espessura de suas paredes.

Palavras-chave: Alvéolos, Brônquio, Bronquíolo, Epitélio

\section{Abstract}

Morphology of the bronchial tree of coati lungs (Nasua nasua, Linnaeus, 1966). The coati (Nasua nasua) is a diurnal, terrestrial and arboricola procionidae. It feeds extensively on the ground and uses trees to procriate, to sleep overnight and to take refuge. Its diet is omnivorous and it feeds on fruits, small vertebrates and 
invertebrates, nectar, eggs and vegetables. The aim of this work was to characterize microscopically the bronchial tree of the coati. Four coatis (two males and two females), fixed in formaldehyde solution 10\%, were used from previous research conducted at CECRIMPAS - UNIFEOB (IBAMA-02027.003731/04-76). For this work, the tissue samples were embedded in paraffin by routine technique and processed for light microscopy in HE staining for analysis under a light microscope. It was found that microscopically, the bronchial tree of the coati is similar to that of other mammals described in the literature, i.e. it has great variations in its architecture, such as a reduced height of the epithelium which changes from ciliated pseudostratified in the larger bronchi to being cubic in the smaller bronchioles, an absence of cilia and glands in the smaller bronchioles, and a decrease in diameter and thickness of its walls.

Key words: Alveolus, Bronchiole, Bronchus, Epithelium

\section{Introdução}

Denver (2003) e Teixeira e Ambrósio (2007) explicam que a família Procyonidae (GRAY, 1825), pertence à ordem Carnívora, à classe Mammalia, ao filo Chordata e ao reino Animalia. A família Procyonidae é divida em duas subfamílias: Procyoninae e Ailurinae, onde os representantes da subfamília Procyoninae são chamados de procionídeos e todos habitam o Novo Mundo. Estão divididos em seis gêneros com 18 espécies. $\mathrm{Na}$ América do Sul encontram-se quatro gêneros: Procyon, Nasua, Potos, Bassaricyon.

Os Procionídeos possuem porte médio, pernas curtas, e pelagem densa. São plantígrados, possuem cinco dedos em cada uma das patas, e, como as suas mãos são móveis possuem habilidade para cavar e são ótimos escaladores. Algumas espécies são totalmente arborícolas e outras forrageiam no chão, porém todas as espécies utilizam as árvores, para repousar, fugir do perigo ou nidificar (DENVER, 2003; TEIXEIRA; AMBRÓSIO, 2007; SANTOS et al., 2010).

Os procionídeos possuem hábito onívoro, que é uma estratégia evolutiva utilizada por muitas espécies animais, visando suprir a escassez de determinado alimento, substituindo por outro sem que haja prejuízo em sua nutrição (HICKMAN et al., 2004).

Os quatis são animais de hábitos diurno, terrestres e arborícolas. Forrageiam extensivamente no chão, utilizando as patas dianteiras para revirar tocos, pedras e explorar buracos a procura de pequenos invertebrados que compõe sua dieta onívora. As garras longas das patas dianteiras também proporcionam segurança na escalada de árvores. O focinho longo e flexível permite explorar ocos de árvores, ninhos e tocas e, por meio do olfato, encontram pequenos vertebrados. Os frutos também são abundantes em sua dieta e são capturados em seu deslocamento sobre as árvores (BEISIEGEL, 2001; TEIXEIRA; AMBRÓSIO, 2007).

Todos os vertebrados são grandes demais para que cada célula interaja diretamente com o ambiente e por esta razão, determinados órgãos compondo um aparelho respiratório, são especializados para suprir a troca gasosa essencial com o ambiente no interesse de todo o corpo. Tal troca é denominada respiração externa e pode ocorrer em determinadas membranas fetais, na superfície da pele, nas brânquias, nos pulmões e ocasionalmente em algum outro local (HILDEBRAND, 1995).

Todas as células do corpo dos animais usam oxigênio e liberam dióxido de carbono, e que o mecanismo no qual estes gases são movimentados para dentro e para fora dos tecidos é a difusão. O oxigênio e o dióxido de carbono são transportados entre os órgãos respiratórios e os outros tecidos através do sistema circulatório. Os gases são então trocados com os tecidos nas respectivas redes capilares, num processo denominado respiração interna, que ocorre nos pulmões (HILDEBRAND, 1995).

O objetivo deste trabalho foi avaliar microscopicamente a árvore brônquica dos quatis, para obtenção de dados que possam levar a um melhor entendimento da anatomia do aparelho respiratório desta espécie.

Considerando a existência de poucos trabalhos descritos sobre a anatomia do quati e a grande representatividade, tanto numérica quanto geográfica destas espécies de carnívoros é importante ressaltar que generalizações quanto ao padrão da anatomia dos quatis (Nasua nasua) devem ser feitas de maneira cautelosa, visto que poucos espécimes foram estudadas detalhadamente (SANTOS et al., 2010). 


\section{Material e Métodos}

Para essa pesquisa foram utilizados três quatis (dois machos e uma fêmea), provenientes do Creatório Científico do Centro Universitário da Fundação de Ensino Octávio Bastos, respeitando os parâmetros internacionais da bioética e bem estar animal conforme preconiza a Comissão de Ética da Faculdade de Medicina Veterinária de São João da Boa Vista (UNIFEOB) com o protocolo 2009.01 e autorizado pelo IBAMA com o processo $\mathrm{n}^{\circ}$ 02027.003731/04-76.

Estes animais foram eutanasiados em 21 de junho de 2008 para utilização em pesquisas anteriores a nossa, portanto não foi necessário o sacrifício de outras vidas para esta pesquisa.

Os pulmões (direito e esquerdo) dos quatis (Nasua nasua) foram retirados após a incisão da região mentoniana até região xifóide com auxílio de bisturi e tesoura, onde os músculos peitorais foram rebatidos lateralmente e em seguida fez-se a desarticulação das costelas do animal na junção costocondral, e dos membros torácicos para a exposição completa do tórax com auxílio de um costótomo.

Com o auxílio de pinça e bisturi, foram extraídas amostras de tecidos com aproximadamente $1,5 \mathrm{~cm}$ cúbicos de cada estrutura pulmonar (brônquios, bronquíolos e parênquima pulmonar), que foram armazenados em frascos contendo álcool a $70 \%$.

Em seguida, as amostras foram desidratadas em uma série de etanóis em concentrações crescentes $(60 \%$ a $100 \%$ ) e diafanizada em xilol, para posterior inclusão em parafina Histosec ${ }^{\circledR}$-Merck (BEHMER, 1976; TOLOSA et al., 2003).

O material foi processado e incluso em blocos de parafina, cortados em micrótomo Leica RM 2155 com espessura média de $5 \mu \mathrm{m}$, sendo os mesmos corados em Hematoxilina/Eosina (H.E) Em seguida as lâminas foram montadas com Entelan e lamínulas para observação da morfologia celular. A fotodocumentação microscópica foi feita através de um fotomicroscópio Leica DM 2000.

A nomenclatura utilizada foi referida conforme o International Committee on Veterinary Gross Anatomical Nomenclature (2005).

\section{Resultados e Discussão}

A árvore brônquica do quati se inicia após o último anel traqueal na região do hilo pulmonar, quando a traqueia se bifurca formando a carina traqueal que origina dois brônquios extrapulmonares (esquerdo e direito) curtos chamados de brônquios primários, concordando com (ISHALQ, 1980) nos cães, Banks (1991) e Samuelson (2007) nos demais carnívoros domésticos (Figura 1).

Os brônquios primários se ramificam emitindo um ramo (lobos secundários ou lobares) para cada um dos quatro lobos pulmonares direitos (cranial, caudal, médio e acessório) e dos dois lobos pulmonares esquerdos (cranial e caudal) do quati, semelhante às descrições de Hare (1975), Ishalq (1980), nos cães, e Samuelson (2007), para os carnívoros domésticos (Figura 1).

Esses brônquios lobares (secundários) se ramificam dando origem a diversos brônquios segmentares (ISHALQ, 1980; BANKS, 1991; TRINDADE et al., 2007) (Figura 1).

Os brônquios primários (extrapulmonares), secundários (lobares) e terciários (segmentares) do quati possuem a mucosa revestida por epitélio do tipo pseudoestratificado ciliado constituído por seis tipos celulares: células caliciformes, células colunares ciliadas, células basais (Figura 2A; 3A), células serosas, células em escova e células do sistema neuroendócrino difuso, sendo estas últimas de difícil visualização ao microscópio de luz, conforme relato de Banks (1991). Gartner e Hiatt (1999) descrevem que todos esses tipos celulares encontrados fazem contato com a membrana basal, mas nem todas alcançam o lúmen, semelhante ao achado no quati, o qual apresenta um epitélio separado da lâmina própria por uma espessa membrana basal semelhante à descrição de Banks (1991) e Samuelson (2007).

$\mathrm{Na}$ lâmina própria dos brônquios primários, secundário e terciário do quati encontramos tecido conjuntivo frouxo, músculo liso disposto em camadas espiraladas, elementos linfóides, glândulas serosas e serocomucosas com seus ductos se abrindo na superfície epitelial, além de uma camada de fibras elásticas separando a lâmina própria da submucosa indo ao encontro do relatado por Banks (1991) e Samuelson (2007), nos mamíferos domésticos. 


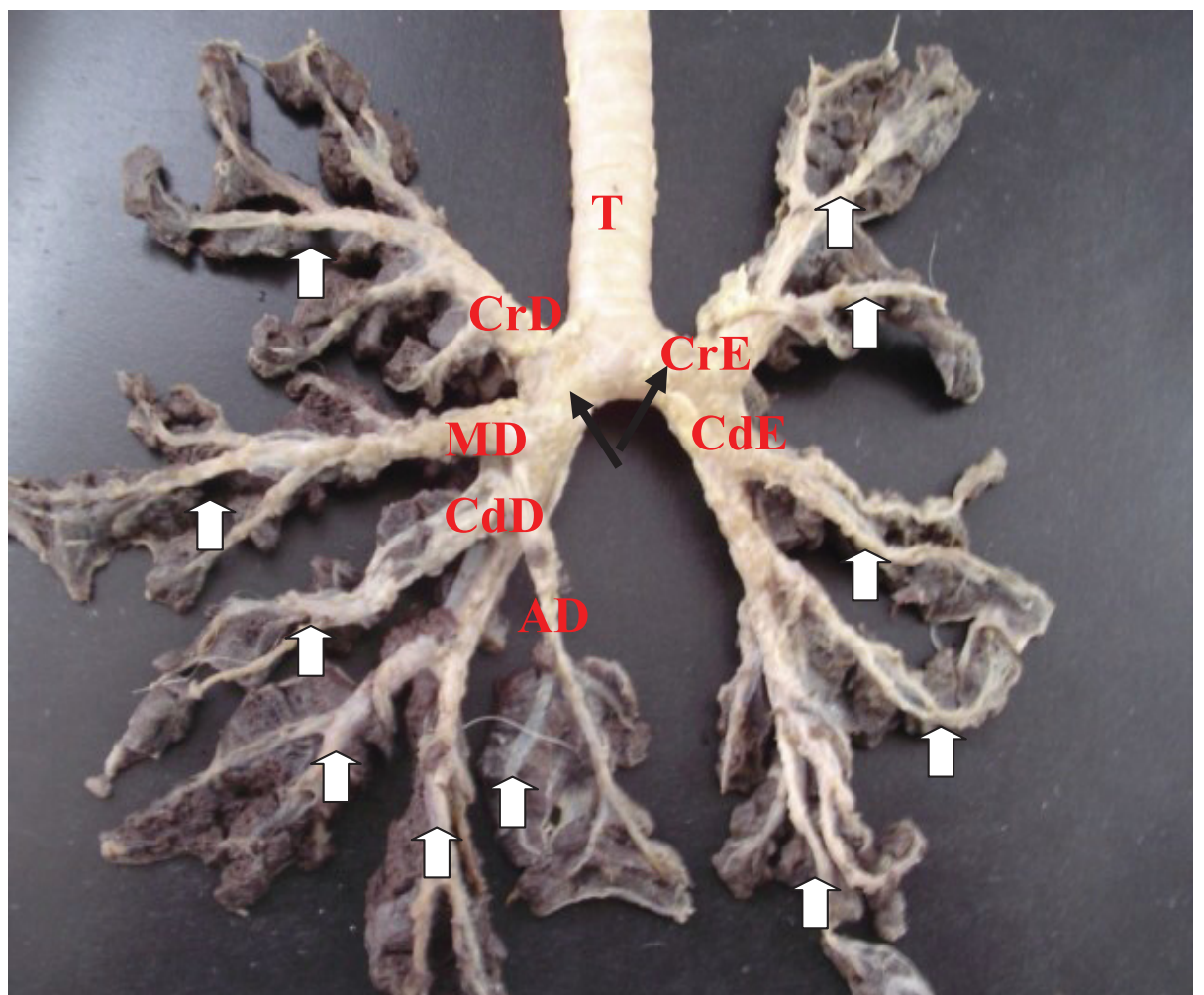

FIGURA 1: Fotografia da árvore brônquica de quati em vista ventral. Observar a disposição da traqueia (T), brônquios principais (primários) direito e esquerdo (seta preta), brônquios intralobares (secundários): ( $\mathrm{CrE})$ cranial esquerdo; ( $\mathrm{CdE})$ caudal esquerdo; (CrD) cranial direito; (MD) medial direito; (CdD) caudal direito e (AD) acessório direito; e brônquios segmentares. (terciários) (seta branca). Técnica de dissecação.
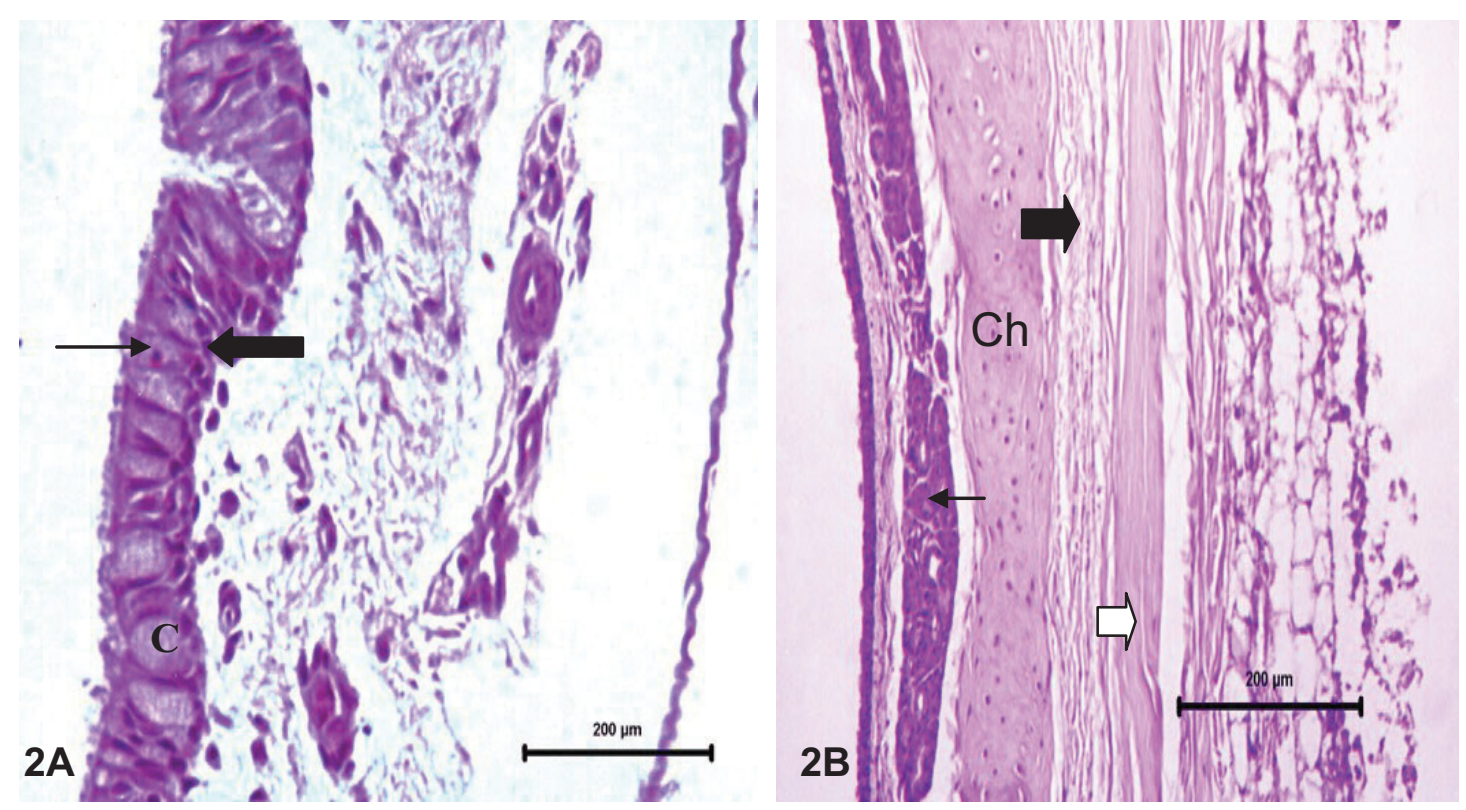

FIGURA 2: Fotomicrografia do brônquio primário do quati. Em A observar no epitélio pseudo estratificado ciliado: células colunares (seta fina); células caliciformes (C) e células basais (seta larga). Destacamos em B ácinos serocomucosos na lâmina própria (seta fina); cartilagem hialina (Ch), fibras elásticas (seta preta) e músculo liso (seta branca) na camada adventícia. Coloração H.E. 
O tecido conjuntivo denso da submucosa apresentou-se irregular com fibras elásticas e glândulas serosas (Figura 3B), além de vasos linfáticos, sanguíneos e elementos linfóides semelhante à descrição de Banks (1991) para os mamíferos domésticos.

$\mathrm{Na}$ camada adventícia dos brônquios primários do quati foram encontradas placas grandes, porém com tamanhos irregulares de cartilagem hialina completada com conexões de músculo liso e fibras elásticas (Figura 2B). O revestimento de tecido conjuntivo frouxo liga o brônquio aos tecidos vizinhos, concordando com Banks (1991) e Samuelson (2007), nos mamíferos domésticos, e Junqueira e Carneiro (1999), nos mamíferos em geral.

Os brônquios primários, secundários (lobares) e terciários (segmentares) do quati, conforme se ramificam, decrescem progressivamente em diâmetro e tamanho, por esse motivo foram observadas várias mudanças, dentre elas a diminuição em quantidade e espessura da cartilagem hialina, a expressa diminuição da quantidade de células caliciformes do epitélio e as células colunares apresentaram-se mais baixas e diminuiram a quantidade de cílios. Sendo assim, tais diferenças fazem com que as paredes dos brônquios diminuam significadamente sua espessura, porém aumenta as quantidades de músculo liso e tecido elástico (Figura 3B), semelhante às descrições de Banks (1991), Dyce et al. (1997), Canals et al. (2002) e Samuelson (2007).

Os brônquios lobares (secundários) que penetram o pulmão do quati se subdividem formando os brônquios terciários (segmentares), que também se arborizam originando os bronquíolos primários, semelhante aos ratos (CANALS et al., 2002) e aos mamíferos domésticos (SAMUELSON, 2007).

O revestimento epitelial dos bronquíolos do quati, assim como do macaco Rhesus (TYLER; PLOPPER, 1985; TYLER et al., 1988) varia de colunar simples com células caliciformes ocasionais, nos maiores bronquíolos, a cúbico simples (muitos com cílios) com ocasionais células de Clara e sem células caliciformes nos menores bronquíolos. Em um mesmo bronquíolo podem ser encontrados epitélios do tipo colunar e cúbico. Resultados semelhantes aos encontrados no quati são encontrados nos demais mamíferos (BANKS, 1991; CANALS et al., 1998; JUNQUEIRA; CARNEIRO, 1999; SAMUELSON, 2007).

As células de Clara são células colunares cuja porção apical em forma de cúpula, possui grossos e curtos microvilos e seu citoplasma apical possui grânulos de secreção que contém glicoproteínas sintetizadas

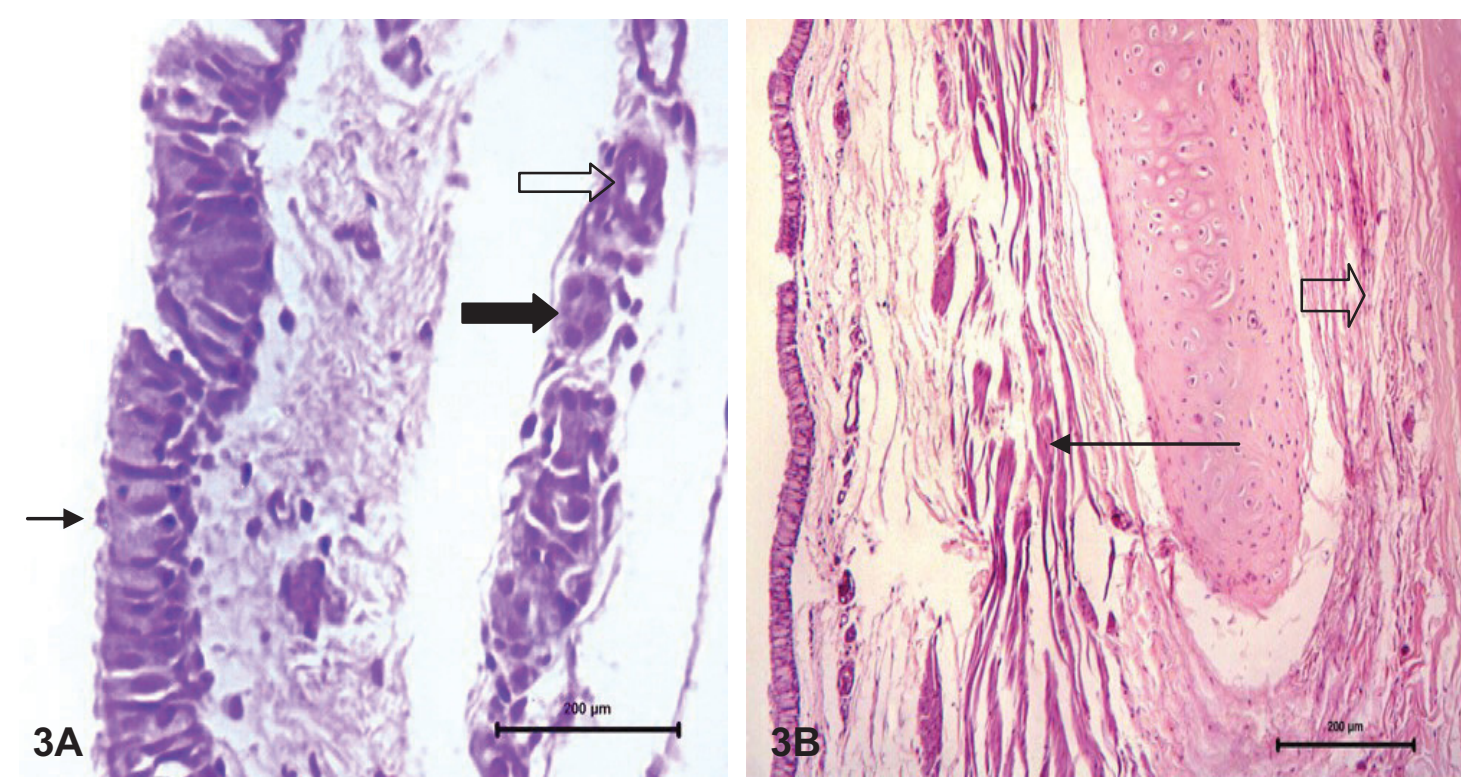

FIGURA 3: Fotografia do brônquio primário e secundário do quati: Em A (brônquio primário) observar o epitélio pseudo estratificado ciliado (seta fina); ácino seroso (seta cheia); ducto do ácino seroso (seta vazia). Enquanto em B (brônquio secundário), elucidamos aumento de músculo liso (seta), tecido elástico (seta larga) e a presença de cartilagem hialina (Ch). Coloração H.E. 
no seu desenvolvido R.E.R. (retículo endoplasmático rugoso). Apresentam como função a proteção do epitélio bronquioalveolar com seus produtos de secreção, além de degradarem toxinas do ar através de enzimas citocromo P-450 em seu retículo endoplasmático liso, e também, as células de Clara dividem-se para regenerar o epitélio bronquiolar (BANKS, 1991; JUNQUEIRA; CARNEIRO, 1999).

A lâmina própria dos bronquíolos do quati semelhante à descrição de Tyler e Plopper (1985) no macaco Rhesus e de Banks (1991) nos demais mamíferos, não possui glândulas, e é circundada por finas camadas de músculo liso. As paredes dos bronquíolos e suas ramificações não possuem cartilagem e fibras elásticas irradiam do tecido conjuntivo fibroelástico que circunda as camadas de músculo liso dos bronquíolos.

Banks (1991) e Poppler e Hyde (2008) explicam que são estas fibras que auxiliam na desobstrução dos bronquíolos, quando estes se tracionam no movimento de expansão do pulmão durante a inalação. As camadas de músculo liso dos bronquíolos são controladas pelo sistema nervoso parassimpático e normalmente estas camadas se contraem ao fim da expiração e relaxam ao fim da inspiração.

Cada bronquíolo do quati se subdivide para formar vários e menores bronquíolos terminais, que possuem epitélio constituído de células de Clara e células cúbicas, podendo ou não apresentar cílios. A lâmina própria dos bronquíolos desse animal é pouco espessa e possui tecido conjuntivo fibroelástico, com camadas de músculo liso, resultados estes semelhantes à descrição de Tyler e Plopper (1985), no macaco Rhesus, e Samuelson (2007), nos demais mamíferos.

Canals et al. (1998), Junqueira e Carneiro (1999) e Samuelson (2007) descrevem que os bronquíolos terminais originam um ou mais bronquíolos respiratórios, que marcam a transição para a porção respiratória do sistema, semelhantes ao resultado encontrado no quati.

Em nossos resultados encontramos que os bronquíolos respiratórios do quati apresentam-se semelhante aos relatos de Tyler e Plopper (1985) no macaco Rhesus e Banks (1991) nos demais mamíferos; apresentando tubos curtos e ramificados, revestido por epitélio simples que varia de colunar baixo a cúbico, semelhante ao dos bronquíolos terminais, podendo apresentar cílios na porção inicial. O músculo liso e as fibras elásticas são bem desenvolvidos, porém formam uma camada mais delgada que a encontrada nos bronquíolos terminais (Figura 4).

Os bronquíolos respiratórios do quati, semelhante ao do macaco Rhesus (TYLER; PLOPPER, 1985; TYLER et al., 1988), possuem suas paredes interrompidas por alvéolos, que tem estruturas em forma de bolsas. Os bronquíolos respiratórios se ramificam, tornando-se mais estreitos em diâmetro e sua população de alvéolos aumenta, formando os ductos alveolares, que por sua vez terminam como bolsas constituídas de grupos de alvéolos conhecidos como saco alveolar, que se abrem dentro de um espaço comum denominado átrio (Figura 4) (BANKS, 1991; CANALS et al., 1998; SAMUELSON, 2007).

Os ductos e sacos alveolares do pulmão do quati são arranjos de alvéolos e são revestidos por um epitélio constituído de células pavimentosas, cuja característica importante é a estreita porção de citoplasma que minimiza a resistência da difusão de gases entre os capilares e os alvéolos, conforme enfatiza Samuelson (2007).

O ducto alveolar possui septos interalveolares, que são constituídos de tecido conjuntivo e se localizam entre os alvéolos, reforçando então o ducto alveolar e auxiliando na estabilização do ducto, semelhante à descrição de Samuelson (2007).

A abertura de cada alvéolo dos pulmões do quati é controlada por células musculares lisas, formando um esfíncter que regula o diâmetro de abertura do alvéolo conforme a descrição de Canals et al. (1998) em ratos e Junqueira e Carneiro (1999) nos mamíferos.

Os alvéolos dos pulmões do quati são revestidos por dois tipos de células, que são os pneumócitos do tipo I e II. Os pneumócitos do tipo I têm a região do núcleo mais larga e abriga a maioria das organelas celulares (pequeno número de mitocôndrias e RER e Golgi pouco desenvolvidos) conforme descrição de Toquetti et al. (2009). Essas células formam zonas de oclusão entre si, evitando o escape do fluído extracelular para dentro do 


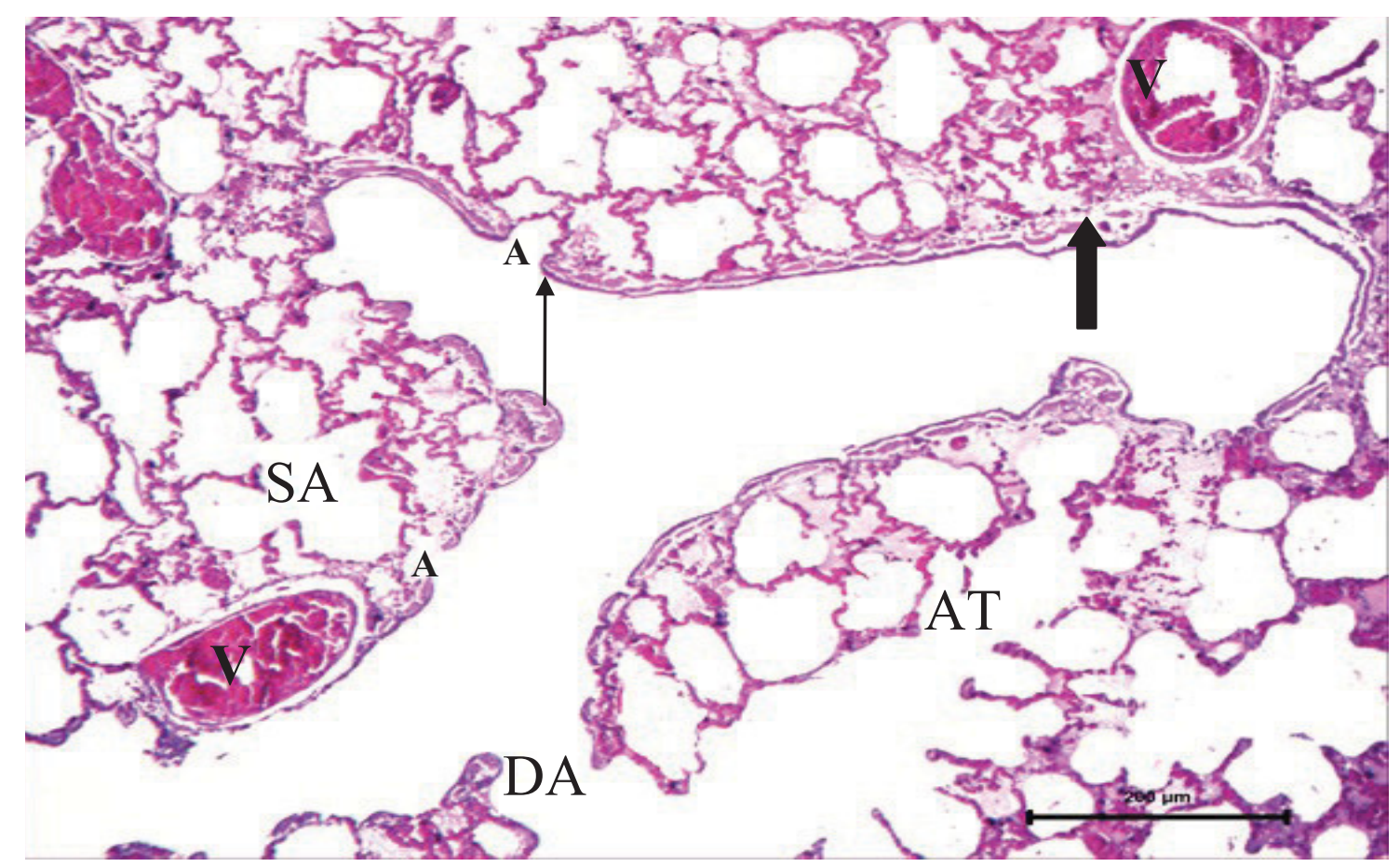

FIGURA 4: Fotomicrografia de um bronquíolo respiratório do quati. Observar a interrupção do epitélio cúbico simples (seta fina) para formação dos alvéolos (A) e sacos alveolares (SA). Notamos também camada de músculo liso (seta cheia); vasos sanguíneos (V); átrios (AT) e ductos alveolares (DA). Coloração H.E.

lúmen alveolar e têm a região basal cobertas por uma lâmina bem desenvolvida, que são ausentes em áreas de poros alveolares (SAMUELSON, 2007; TOQUETTI et al., 2009).

Os pneumócitos do tipo II nos alvéolos dos pulmões do quati ocupam apenas uma diminuta porção da superfície alveolar, semelhante aos bovinos (TOQUETTI et al., 2009) e demais mamíferos domésticos (SAMUELSON, 2007). São células cúbicas e formam zonas de oclusão com os pneumócitos do tipo I. Sua superfície projeta-se para dentro do lúmen do alvéolo e possuem núcleo situado centralmente.

Constatou-se que microscopicamente a árvore brônquica dos quatis é semelhante a dos demais mamíferos descritos na literatura consultada, possuindo grandes variações em sua arquitetura conforme a árvore brônquica se ramifica, decrescendo em diâmetro e espessura de suas paredes.

\section{Agradecimentos}

À FAPESP (Fundação de Amparo a Pesquisa do Estado de São Paulo), por permitir a dedicação em período integral do primeiro autor, à UNIFEOB pelo incentivo a pesquisa científica e ao IBAMA por licenciar o uso dos animais desta pesquisa.

\section{Referências}

BANKS, W. J. Histologia Veterinária Aplicada. $2^{\text {a }}$ ed. São Paulo: Manole, 1991. $629 \mathrm{p}$.

BEHMER, O. A. Manual de técnicas para histologia normal e patológica. São Paulo: Edart, 1976. 241 p.

BEISIEGEL, B. M. Notes on the Coati, Nasua nasua (Carnívora: Procyonidae) in an Atlantic Forest area. Brazilian Journal of Biology, São Carlos, v. 61, n. 4, p. 689-692, 2001.

CANALS, M. ; ATALA, C. ; OLIVARES, R. ; NOVOA, F. F. ; ROSENMANN, M. La asimetria y el grado de optimizacion del arbol bronquial en Rattus norvegicus y Orictolagus cuniculus. Revista Chilena de Historia Natural, Santiago, v. 75, n. 2, p. 271282, 2002.

CANALS, M.; OLIVARES, R.; LABRA, F.; CAPITO, L.; RIVERA, A.; NOVOA, F. F. Caracterización de la geometria fractal del árbol bronquial en mamíferos. Revista Chilena de Anatomia, Temuco, v. 16, n. 2, p. 237-244, 1998. 
DENVER, M. Procionidae and Viverridae. In: FOWLER, M.; MILLER, R. E. (Eds). Zoo and Wild Animal Medicine. $5^{\text {th }}$ ed. Missouri: Saunders, 2003. p. 516-523.

DYCE, K. M.; SACK, W. O.; WENSING, C. J. G. Tratado de Anatomia Veterinária. $2^{\mathrm{a}}$ ed. Rio de Janeiro: Guanabara Koogan, 1997. $633 \mathrm{p}$.

GARTNER, L. P.; HIATT, J. L. Tratado de Histologia. Rio de Janeiro: Guanabara Koogan, 1999. 414 p.

HARE, W. C. D. Sistema Respiratório do Carnívoro. In: GETTY, R. (Ed.). Anatomia do Animais Domésticos. Vol. 2. $5^{\mathrm{a}}$ ed. Rio de Janeiro: Guanabara Koogan, 1975. p. 1465-1479.

HICKMAN, C. P. J.; ROBERTS, L.; LARSON, A. Princípios Integrados de Zoologia. $11^{\text {a }}$ ed. Rio de Janeiro: Guanabara Koogan, 2004. 846 p.

HILDEBRAND, M. Análise da Estrutura dos Vertebrados. São Paulo: Atheneu, 1995. $700 \mathrm{p}$

INTERNATIONAL COMMITTEE ON VETERINARY GROSS ANATOMICAL NOMENCLATURE. Nomina Anatomica Veterinaria. $5^{\text {th }}$ ed. Hannover: Columbia, Gent, Sapporo, 2005. $165 \mathrm{p}$.

ISHALQ, M. A. Morphological study of the lungs and bronchial tree of the dog: with a suggested system of nomenclature for bronchi. Journal of Anatomy, Maiden, v. 131, n. 4, p. 589-610, 1980.

JUNQUEIRA, L. C.; CARNEIRO, J. Histologia Básica. $9^{a}$ ed. Rio de Janeiro: Guanabara Koogan, 1999. 488 p.

POPPLER, C. G.; HYDE, D. M. The non-human Primates as a model for studing COPD and Asthma. Pulmonary Pharmacology \& Therapeutics, London, v. 21, n. 5, p. 755-766, 2008.

REGINATO, A. L.; MELO, A. P. F. Segmentação anátomo-cirúrgica em baços de queixada (Tayassu pecari - Link, 1975). Brazilian Journal of Veterinary Research and Animal Science, São Paulo, v. 41, n. 4 , p. $281-285,2004$.
SAMUELSON, D. A. Tratado de Histologia Veterinária. Rio de Janeiro: Elsevier, 2007. 527 p.

SANTOS, A. C. BERTASSOLI, B. M.; OLIVEIRA, V. C.; CARVALHO. A. F.; ROSA. R. A.; MANÇANARES, C. A. F. Morfologia dos músculos do ombro, braço e antebraço do quati (Nasua nasua, Linnaeus, 1758). Biotemas, Florianópolis, v. 23, n. 3, p. 167-173, 2010.

TEIXEIRA, R. H. F.; AMBRÓSIO, S. R. Carnívora-Proyonidae In: CUBAS, Z. S.; SILVA, J. C. R.; DIAS, J. C. (Eds). Tratado de Animais Selvagens. São Paulo: Roca, 2007. p. 571-573.

TOLOSA, E. M. C.; RODRIGUES, C. J.; BEHMER, O. A.; FREITAS NETO, A. G. Manual de técnicas para histologia normal e patológica. $2^{\mathrm{a}}$ ed. Barueri: Manole, 2003. $331 \mathrm{p}$.

TOQUETTI, R. C.; GUERRA, R. R.; AMBRÓSIO, C. E.; SANTOS, J. M.; FAVARON, P. E.; FRANCIOLI, A. L. R.; ALBERTO, M. V.; MEIRELLES, F. V.; MIGLINO, M. A. Morfologia e funcionalidade do pneumócito tipo II e sua relação e variação com a idade gestacional em bovinos. Ciência Rural, Santa Maria v. 39, n. 8, p. 2470-2477, 2009.

TRINDADE, S. H. K. ; MELLO-JUNIOR, J. F.; MION, O. G.; LORENZI-FILHO, G.; MACHIONE, M.; GUIMARÃES, E. T.; SALDIVA, P. H. N. Métodos de estudo do transporte mucociliar. Revista Brasileira de Otorrinolaringologia, Rio de Janeiro, v. 73, n. 5, p. 704-712, 2007.

TYLER, N. K.; PLOPPER, C. G. Morphology of the distal conducting airways in Rhesus monkey lungs. Anatomical Record, Philadelphia, v. 211, n. 3, p. 295-303, 1985.

TYLER, N. K.; HYDE, D. M.; HENDRICKX, A. G.; PLOPPER, C. G. Morphogenesis of the respiratory bronchiole in Rhesus monkey lungs. American Journal of Anatomy, Philadelphia, vol. 182, n. 3, p. 215-223, 1988. 